\title{
Cue Reactivity in Active Pathological, Abstinent Pathological, and Regular Gamblers
}

\author{
Ruthlyn Sodano $\cdot$ Edelgard Wulfert
}

Published online: 7 August 2009

(C) The Author(s) 2009. This article is published with open access at Springerlink.com

\begin{abstract}
Twenty-one treatment-seeking pathological gamblers, 21 pathological gamblers in recovery, and 21 recreational gamblers watched two video-taped exciting gambling scenarios and an exciting roller-coaster control scenario while their arousal (heart rate and subjective excitement) and urge to gamble were being measured. The gamblers did not differ significantly in cue-elicited heart rate elevations or excitement. However, the active pathological gamblers reported significantly greater urges to gamble across all cues compared to the abstinent pathological gamblers and, with marginal significance $(p=0.06)$, also compared to the social gamblers. Further exploration of these findings revealed that active pathological gamblers experience urges to gamble in response to exciting situations, whether or not they are gambling related, whereas abstinent and social gamblers only report urges to an exciting gambling-related cue. This suggests that for pathological gamblers excitement itself, irrespective of its source, may become a conditioned stimulus capable of triggering gambling behavior. Implications for treatment and future research are discussed.
\end{abstract}

Keywords Pathological gambling $\cdot$ Cue reactivity $\cdot$ Urge $\cdot$ Excitement ·

Addiction

\section{Introduction}

Research on the nature of pathological gambling has been sparse and we do not have a good understanding of the factors that lead to its development. One reason may be that a comprehensive theory of pathological gambling built from a solid empirical basis has yet to be developed. Pathological gambling is classified as an impulse control disorder in the

R. Sodano - E. Wulfert

University at Albany, State University of New York, Albany, USA

R. Sodano $(\bowtie)$

UCLA Integrated Substance Abuse Programs, 1640 S. Sepulveda Blvd, Suite 200, Los Angeles,

CA 90025, USA

e-mail: rsodano@mednet.ucla.edu 
Diagnostic and Statistical Manual of Mental Disorders, Fourth Edition, Text Revision (DSM-IV-TR) (American Psychiatric Association 2000), but shares many important features with addictive disorders (e.g., alcohol or substance dependence), for which empirically grounded, well-formulated conceptual models exist. It would therefore seem appropriate to explore the fit and usefulness of existing models of addiction for a better understanding of pathological gambling. The cue reactivity paradigm is one such model.

The cue reactivity paradigm is derived from a classical conditioning framework and has been used extensively in drug and alcohol use research to explore an individual's physiological and subjective reactions elicited by drug-related stimuli that have been associated with previous episodes of substance use (Carter and Tiffany 1999). This paradigm has proven useful in studying basic theoretical issues related to our understanding of addictive behaviors (Drummond et al. 1995; Carter and Tiffany 1999). It is postulated that certain stimuli or cues (e.g., sights, sounds, environmental contexts, or internal states such as tension or boredom), through their repeated pairing with the addictive behavior (e.g., substance use), become capable of eliciting distinctive patterns of physiological responses (e.g., increased heart rate) as well as psychological reactions (e.g., cravings or urges). These elicited response patterns serve as the motivational basis for engaging in the addictive (e.g., drug-seeking) behavior and the behavior increases in probability through operant conditioning because the drug effects are positively reinforcing. Thus, the drugrelevant stimuli become conditioned stimuli that elicit central motivational states producing physiological responses consistent with the direct, positively reinforcing properties of the drug (Stewart et al. 1984).

A number of empirical studies have shown that substance dependent individuals show significant physiological and subjective reactions to drug-related stimuli (e.g., Rohsenow et al. 1990). For example, in one study (Robbins et al. 2000) cocaine-dependent individuals were exposed to cocaine-related cues (e.g., an audiotape of people discussing cocaine injections) and neutral stimuli (e.g., excerpt from a nature video). Arousal measured via heart rate, skin conductance, and subjective report was significantly greater in response to cocaine-specific compared to neutral cues.

These conditioned reactions have not only proved useful in elucidating the acquisition of addictive behaviors but have also been used to explain relapse, which is thought to occur through exposure to relevant cues that provoke spontaneous recovery following a period of abstinence (Childress et al. 1986; Siegel 1979; Stewart et al. 1984; Wikler 1965). Most importantly, findings from this research have also been used to develop new treatments for substance abuse based on cue exposure in an attempt to extinguish the learned response disorders (Brandon et al. 1995; Dawe and Powell 1995; Rohsenow et al. 1995).

A small but growing body of research suggests that the cue reactivity paradigm is also useful in understanding behavioral addictions such as pathological gambling. It is assumed that gambling is initially acquired through the effects of positive reinforcement (intermittent monetary wins). Contact with a generalized reinforcer (money) elicits excitement and physiological arousal. Over time, these autonomous reactions not only generate the desire to gamble but generalize via Pavlovian conditioning to other stimuli and eventually become elicited by a wide range of external situations and internal mood states that have been associated with gambling. The elicitation power of these cues is maintained by occasional wins that occur on a random ratio schedule.

A number of studies have shown that gambling is associated with increased physiological arousal and subjective excitement. These reactions to gambling-related cues have been demonstrated in the laboratory (Ladouceur et al. 2003; Wulfert et al. 2005, 2008) and in naturalistic studies (Coventry and Norman 1997; Moodie and Finnigan 2005). They have 
even been shown in response to gamblers simply describing or imagining gambling scenes (Blanchard et al. 2000; Sharpe 2004). There is also some evidence that high-frequency gamblers may react with greater heart rate arousal than low-frequency gamblers (Leary and Dickerson 1985; Dickerson and Adcock 1987). However, this phenomenon has not been observed uniformly because a number of studies have not found HR differences among high- and low-frequency gamblers (e.g., Sharpe et al. 1995; Coventry and Norman 1997).

Based on conditioning theory, reactivity to gambling stimuli presumably extinguishes through repeated cue exposure and response prevention, although extinction can be remarkably context-specific, which may lead to the reinstatement of the response in a different context (Bouton 2004; Bouton et al. 2006). Nevertheless, if pathological gamblers have learned to manage the urge to gamble in a variety of contexts and have remained abstinent, they may show less reactivity to gambling cues than those who are actively gambling. While this assumption to date has not been empirically demonstrated in the gambling literature, there is evidence in the alcohol and drug literature that this is indeed the case (e.g., Anton et al. 1996; O'Brien et al. 1990). The present study was designed to fill a gap in the literature and to examine possible differences in cue reactivity in diagnosed pathological gamblers compared to currently abstinent pathological gamblers as well as regular social gamblers.

\section{Method}

Participants

Participants were 63 gamblers (49 men and 14 women), including 21 active pathological gamblers ( 15 male, 6 female), 21 currently abstinent ( $\geq 3$ months) pathological gamblers (20 male, 1 female), and 21 social gamblers ( 14 male, 7 female) who never gambled excessively. All participants were of legal gambling age (mean age 47 years, $S D=13.4$, range 20-73 years); most were Caucasian (89\%), followed by African American (4.8\%), Hispanic (4.8\%), and Asian (1.6\%). Individuals with a likely current diagnosis of alcohol or substance abuse/dependence as measured by the Addiction Severity Index (McLellan et al. 1992) or those with a brain disorder (psychosis, dementia) as determined by participant response to questions regarding past and present diagnoses and medication history were excluded.

\section{Design}

The study followed a three (type of gambler: pathological, abstinent, social) by three (type of scenario: win, lose, rollercoaster) design. The main dependent variables were heart rate, subjective excitement, and urge to gamble.

\section{Measures}

Participant's gambling status was assessed using the National Opinion Research Center (National Opinion Research Center 1999) DSM-IV Screen for Gambling Problems (NODS). The NODS is a DSM-IV-TR (American Psychiatric Association 2000) based 17-item diagnostic screen that yields a score between 0 and 10 and assesses the 10 DSM-IV criteria for pathological gambling. A score of $\geq 5$ indicates pathological gambling. The NODS has well-established psychometric properties, including strong testretest reliability and high internal consistency (National Opinion Research Center 1999). 
The drug and alcohol domains of the Addiction Severity Index (ASI: McLellan et al. 1992) were used to screen out individuals with current alcohol or drug use disorders. The ASI is a semi-structured interview that yields reliable and valid indices of alcohol- and drug-related problems, with internal consistency coefficient alphas of 0.67 for drug problems and 0.88 for alcohol problems (McLellan et al. 1992).

The stimulus materials were DVD clips of 2-min duration each. Separate stimuli were created for the most common gambling activities reported by treatment-seeking gamblers in a pilot study at a local center for problem gambling. Separate DVD clips were created for each of these activities, one depicting a winning and one a losing scenario. A third DVD clip of an exciting rollercoaster scene served as control cue due to its nonspecific arousing quality. The visual displays on all DVDs were accompanied by two sound tracks, one consisting of authentic background sounds specific to the gambling activities and the other a male voice-over describing in detail the depicted activities and instructing the participant to experience as vividly as possible specific cognitive, physical, and emotional reactions (a sample transcript of a DVD is presented in the appendix). Prior to each stimulus presentation, relaxation instructions were provided followed by relaxing music. These DVD stimulus materials were modeled after an audiotaped version used in a study by Blanchard et al. (2000) in which tape recorded scripts were used to guide imagination of gambling scenarios. In our adaptation, we added visual (e.g., pictures of gambling scenes) and auditory (e.g., sounds of slot machines) stimuli because there is evidence in the research literature that more complex stimuli elicit a more robust response (e.g., Kuntze et al. 2001; Lee et al. 2003). The use of complex rather than unisensory stimuli is desirable because in the real world most events generate stimulation via multiple sensory channels that are integrated into a unified representation of the world (Ethofer et al. 2006) and that show positive effects on behavioral reactions both in humans (Miller 1986; Schroger and Widmann 1998) and animals (Gingras et al. 2009).

Physiological arousal, subjective excitement, and urge to gamble served as the dependent variables. Physiological arousal, indexed by heart rate in beats per minute (BPM), was recorded continuously in 5s intervals with a Polar S610i exercise heart rate monitor. The signals were transmitted wirelessly from a chest strap to a wristwatch-like receiver and were later transferred to a computer. At the end of each DVD clip, participants were asked to provide subjective ratings on a $0-10$ scale of their current level of excitement $(0=$ no excitement; $10=$ extreme excitement $)$ and their current urge to gamble $(0=$ no urge; $10=$ extreme urge $)$. This method was adapted from Wulfert et al. (2005).

\section{Procedure}

All procedures were approved by the university's institutional review board. The pathological gamblers were treatment-seeking patients recruited from a local clinic after completing intake procedures but before beginning treatment; the abstinent pathological gamblers were recruited from Gamblers Anonymous meetings; and the social gamblers were recruited via newspaper advertisements and flyers from the community. A brief telephone screen determined potential eligibility in terms of gambling frequency and severity. Those that met initial criteria for gambling at least monthly currently or in the past were scheduled for an in-person interview. After obtaining informed consent, all potential participants were administered a brief clinical interview about their mental health and medication history. The ASI was administered to assess problematic drug and alcohol use. Individuals with dementia, a past or current diagnosis of a psychotic disorder, or current alcohol or substance dependence were deemed ineligible for the study. The NODS 
was also administered to determine if participants met DSM-IV criteria for past or current pathological gambling or were considered social gamblers.

Two participants were excluded from the study due to current substance dependence and one participant was excluded for a diagnosis of schizophrenia. Eight participants were deemed ineligible because they had met criteria for pathological gambling in the past though not currently, but also gambled in the past 3 months and thus did not fit into any of the three categories. These eleven participants were compensated $\$ 35$ in gift cards for their time, and the interview ended. Those who were eligible continued with the cue reactivity procedures.

The final sample $(N=63)$ consisted of three groups of 21 participants each. The pathological gamblers met current DSM-IV criteria as measured by the NODS and their most recent gambling episode was on average 8.9 days $(S D=11.5)$ prior to the assessment. The abstinent pathological gamblers met lifetime but not current DSM-IV criteria for pathological gambling on the NODS and had not gambled for at least 3 months. [3 months were identified as a reasonable period of abstinence by Daughters et al. (2005), and Hodgins et al. (2005); but shorter periods have also been used; e.g., (Blaszczynski et al. 1991); (Petry 2003).] On average, participants in this group last gambled 2.5 years ago ( $S D=4.4$; range 97 days to 17.5 years). The social gamblers gambled at least once a month during the past 3 months and had never met criteria for pathological gambling in their lifetime as measured by the NODS. The most recent gambling episode for this group was an average of 6.1 days $(S D=8.1)$ prior to the assessment.

For the cue reactivity procedure, participants fitted the heart rate monitor in privacy and then were seated comfortably in an upholstered chair and watched a display on a computer monitor. Instructions and the sound track for the video clips were presented via headphones. Heart rate was recorded continuously via a wireless receiver positioned out of the participant's sight. The experimenter remained in the room, sitting at a distance behind the participant.

The psychophysiological assessment was modeled after procedures used by Blanchard et al. (2000). After an adaptation phase and instructions to relax, participants were exposed to two scenarios of their preferred gambling activity (one a winning, the other a losing scenario, presented in counterbalanced order) and an exciting non-gambling scenario (rollercoaster scene) that served as a non-specific arousal stimulus. The rollercoaster scene as a control cue was included to assess the specificity of cue reactivity to an exciting gambling cue versus any exciting cue. It was always presented last so as not to have a generic arousal cue exert a possible priming effect on the gambling cues (see Blanchard et al. 2000; Wulfert et al. in press). Before each scenario participants were instructed to sit quietly for $2 \mathrm{~min}$ and rest comfortably while listening to calm and relaxing music for a return to baseline; after each scenario, participants rated their excitement and urge to gamble on a $0-10$ scale. The instructions and sequence of cue presentations are presented in Table 1.

At the conclusion of the study, participants were debriefed and received \$35 in gift certificates as compensation for their time and effort.

\section{Results}

Preliminary Analyses

Assumptions of normality, homogeneity of variance, linearity, and multicollinearity were met satisfactorily for all variables except baseline-corrected heart rate, which was 
Table 1 Sequence of instructions and cue presentations

\begin{tabular}{|c|c|c|}
\hline Condition & Length & Instructions \\
\hline Adaptation & $3 \mathrm{~min}$ & $\begin{array}{l}\text { Please relax. You will hear my voice instructing you throughout this } \\
\text { assessment. }\end{array}$ \\
\hline Baseline 1 & $2 \mathrm{~min}$ & $\begin{array}{l}\text { Please sit quietly and relax as you listen to the music. You may close your } \\
\text { eyes if you like. }\end{array}$ \\
\hline Subjective ratings 1 & $30 \mathrm{~s}$ & $\begin{array}{l}\text { On a scale from } 0 \text { to } 10 \text { : } \\
\text { - How relaxed are you feeling right now? } \\
\text { - How excited are you feeling right now? } \\
\text { - How strong is your urge to gamble right now? }\end{array}$ \\
\hline Gambling scenario 1 & $2 \mathrm{~min}$ & $\begin{array}{l}\text { While directing your attention to the screen in front of you, please } \\
\text { visualize the following scene as vividly as you can. }\end{array}$ \\
\hline Subjective ratings 2 & $20 \mathrm{~s}$ & $\begin{array}{l}\text { On a scale from } 0 \text { to } 10 \text { : } \\
\text { - How excited are you feeling right now? } \\
\text { - How strong is your urge to gamble right now? }\end{array}$ \\
\hline Baseline 2 & $2 \mathrm{~min}$ & $\begin{array}{l}\text { Please sit quietly and relax as you listen to the music. You may close your } \\
\text { eyes if you like. }\end{array}$ \\
\hline Gambling scenario 2 & $2 \mathrm{~min}$ & $\begin{array}{l}\text { While directing your attention to the screen in front of you, please } \\
\text { visualize the following scene as vividly as you can. }\end{array}$ \\
\hline Subjective ratings 3 & $20 \mathrm{~s}$ & $\begin{array}{l}\text { On a scale from } 0 \text { to } 10 \text { : } \\
\text { - How excited are you feeling right now? } \\
\text { - How strong is your urge to gamble right now? }\end{array}$ \\
\hline Baseline 3 & $2 \mathrm{~min}$ & $\begin{array}{l}\text { Please sit quietly and relax as you listen to the music. You may close your } \\
\text { eyes if you like. }\end{array}$ \\
\hline Rollercoaster scene & $2 \mathrm{~min}$ & $\begin{array}{l}\text { While directing your attention to the screen in front of you, please } \\
\text { visualize the following scene as vividly as you can. }\end{array}$ \\
\hline Subjective ratings 4 & $20 \mathrm{~s}$ & $\begin{array}{l}\text { On a scale from } 0 \text { to } 10 \text { : } \\
\text { - How excited are you feeling right now? } \\
\text { - How strong is your urge to gamble right now? }\end{array}$ \\
\hline End of assessment & $20 \mathrm{~s}$ & $\begin{array}{l}\text { Thank you. The assessment is now complete. You may now remove } \\
\text { the headphones and the heart rate monitor. }\end{array}$ \\
\hline
\end{tabular}

square-root transformed for the analyses. For ease of interpretation, untransformed means and standard deviations have been reported in the tables.

No statistically significant group differences were found for demographic variables of age $[F(2,60)=1.40, p=0.254]$, gender $\left[\chi^{2}(2, N=63)=5.69, p=0.058\right]$, or ethnicity $\left[\chi^{2}(6, N=63)=10.57, p=0.103\right]$. Further, there were no significant group differences in baseline measures of heart rate $[F(2,60)=0.407, p=0.667]$, excitement $[F(2,60)=$ $1.69, p=0.194]$, or urge to gamble $[F(2,60)=2.90, p=0.063]$.

As expected, a one-way ANOVA showed significant differences among groups in terms of abstinence, $F(2,60)=6.66, p=0.002$. Follow-up Sidak-adjusted comparisons showed that the abstinent pathological gambling group had significantly more time abstinent compared to both active pathological gamblers $(p=0.008)$ and social gamblers $(p=0.007)$. The latter two groups did not differ significantly from each other $(p=1.00)$.

\section{Descriptive Information}

The preferred gambling activity of the participants was betting on horses (31.7\%), followed by scratch-off lottery games $(22.2 \%)$, slot machine gambling (19\%), blackjack $(7.9 \%)$, sports betting $(6.3 \%)$, and poker $(4.8 \%) ; 8.1 \%$ stated idiosyncratic activities such 
as online poker, stock trading, and bingo. There were no significant differences between the three groups in preferred gambling activities $\left[\chi^{2}(12, N=63)=9.70, p=0.642\right]$. Fifty-three out of 63 participants $(84.1 \%)$ were shown a DVD that matched their preferred type of gambling. Seven participants $(11.1 \%)$ were shown a DVD that matched their second-most preferred gambling type, and three participants $(4.8 \%)$ were shown a type of gambling they felt would be most similar to their preferred type of gambling (e.g., harness racing versus horse racing).

\section{Cue Reactivity Analyses}

We conducted a repeated-measures multivariate analysis of variance (MANOVA) with scenario (win, lose, rollercoaster) as the within-subjects factor and group (pathological, abstinent, social gamblers) as the between-subjects factor. The dependent variable was cue-elicited arousal, measured both as a physiological manifestation (baseline corrected maximum heart rate) and its psychological interpretation (subjective rating of excitement). Means and standard deviations are summarized in Table 2. The MANOVA yielded a significant main effect for scenario [Wilks' $\Lambda=0.576, F(2,59)=21.69, p<0.001$, $\left.\eta^{2}=0.58\right]$. The main effect for group $[F(2,60)=0.24, p=0.791]$ and the interaction of group by scenario $[F(4,118)=1.76, p=0.142]$ were non-significant. Follow-up ANOVAs showed no heart rate differences in response to the three scenarios [Wilks' $\left.\Lambda=0.930, F(2,59)=2.21, p=0.119, \eta^{2}=0.07\right]$, but participants reported significantly less excitement $(M=3.59, S D=0.35)$ in response to the lose scenario compared to the win $(M=5.29, S D=0.31)$ and the rollercoaster scenario $(M=5.56, S D=0.32)$ [Wilks' $\left.\Lambda=0.621, F(2,59)=18.04, p<0.001, \eta^{2}=0.38\right]$; the latter two did not differ from each other $(p=0.792)$.

We conducted a repeated-measures ANOVA for urge to gamble, the motivational state thought to emerge as a result of the objective (heart rate) and subjective (excitement) manifestation of arousal. For this analysis, scenario (win, lose, rollercoaster) served as the within-subjects factor and group (pathological, abstinent, social gamblers) as the betweensubjects factor. For means and standard deviations see Table 3. This analysis yielded significant main effects for group $\left[F(2,60)=5.67, p=0.006, \eta^{2}=0.16\right]$ and scenario [Wilks' $\Lambda=0.575, F(2,59)=21.83, p<0.001, \eta^{2}=0.43$ ] and a significant interaction of group by scenario [Wilks' $\Lambda=0.821, F(4,118)=3.05, p=0.020, \eta^{2}=0.09$ ].

Table 2 Means and standard deviations of baseline corrected heart rate elevations (beats per minute) and subjective excitement by condition

\begin{tabular}{|c|c|c|c|c|c|c|}
\hline \multirow[t]{2}{*}{ Condition } & \multicolumn{2}{|c|}{ Active $(n=21)$} & \multicolumn{2}{|c|}{ Abstinent $(n=21)$} & \multicolumn{2}{|c|}{ Social $(n=21)$} \\
\hline & $M$ & $S D$ & $M$ & $S D$ & $M$ & $S D$ \\
\hline \multicolumn{7}{|l|}{ Heart rate } \\
\hline Win scenario & $4.8_{\mathrm{a}}$ & 3.46 & $6.2_{\mathrm{a}}$ & 4.73 & $6.2_{\mathrm{a}}$ & 5.22 \\
\hline Lose scenario & $4.3_{\mathrm{a}}$ & 3.62 & $5.9 \mathrm{a}$ & 5.35 & $5.4_{\mathrm{a}}$ & 4.61 \\
\hline Rollercoaster scenario & $4.9 \mathrm{a}$ & 4.44 & $7.7 \mathrm{a}$ & 5.26 & $6.2 \mathrm{a}$ & 4.77 \\
\hline \multicolumn{7}{|l|}{ Subjective excitement } \\
\hline Win scenario & $6.1_{\mathrm{a}}$ & 2.77 & $4.3 \mathrm{a}$ & 2.22 & $5.4_{\mathrm{a}}$ & 2.46 \\
\hline Lose scenario & $3.4_{\mathrm{b}}$ & 3.39 & $3.7 \mathrm{a}$ & 2.65 & $3.7_{\mathrm{b}}$ & 2.22 \\
\hline Rollercoaster scenario & $5.9 \mathrm{a}$ & 2.49 & $5.1_{\mathrm{a}}$ & 2.03 & $5.6_{\mathrm{a}}$ & 2.99 \\
\hline
\end{tabular}

Note: Means within a column with different subscripts are significant (Sidak adjustment, $p<0.05$ ) 
Table 3 Means and standard deviations of urge to gamble by condition

\begin{tabular}{|c|c|c|c|c|c|c|}
\hline \multirow[t]{2}{*}{ Condition } & \multicolumn{2}{|c|}{ Active $(n=21)$} & \multicolumn{2}{|c|}{ Abstinent $(n=21)$} & \multicolumn{2}{|c|}{ Social $(n=21)$} \\
\hline & $M$ & $S D$ & $M$ & $S D$ & $M$ & $S D$ \\
\hline \multicolumn{7}{|l|}{ Urge to gamble: } \\
\hline Win scenario & $6.0_{\mathrm{a}}$ & 3.07 & $2.5_{\mathrm{a}}$ & 3.20 & $3.6_{\mathrm{a}}$ & 3.27 \\
\hline Lose scenario & $3.3_{\mathrm{b}}$ & 2.70 & $1.7_{\mathrm{a}, \mathrm{b}}$ & 2.37 & $2.2_{\mathrm{b}}$ & 2.79 \\
\hline Rollercoaster scenario & $4.5_{\mathrm{c}}$ & 2.99 & $1.5_{\mathrm{b}}$ & 2.25 & $2.2_{\mathrm{b}}$ & 2.57 \\
\hline
\end{tabular}

Note: Means within a column with different subscripts are significant (Sidak adjustment, $p<0.05$ )

Collapsing across scenarios, Sidak-corrected post-hoc analyses revealed that active pathological gamblers reported higher urges to gamble $(M=4.57, S D=0.57)$ than the abstinent pathological gamblers $(M=1.92, S D=0.57 ; p=0.005)$; the social gamblers $(M=2.67, S D=0.57)$ fell in between and did not differ from the abstinent pathological gamblers $(p=0.740)$ but differed marginally $(p=0.065)$ from the pathological gamblers. Collapsing across groups, the urge to gamble was highest in response to the win scenario $(M=4.02, S D=0.40 ; p<0.001)$; the lose $(M=2.40, S D=0.33)$ and rollercoaster $(M=2.75, S D=0.33)$ scenarios were both lower and did not differ from each other $(p=0.196)$. An examination of the interaction effect showed that the active pathological gamblers reported the highest urge to gamble in response to the winning scenario $(M=5.95, S D=0.69)$, followed by the exciting rollercoaster scene $(M=4.48$, $S D=0.57)$ and lastly the losing scenario $(M=3.29, S D=0.57)[F(2,59)=18.41$, $\left.p<0.001, \eta^{2}=0.38\right]$. All were significantly different from each other at $p$-values of $\leq 0.001$. The abstinent pathological gamblers also reported a greater urge to gamble to the winning scenario $(M=2.52, S D=0.69)$; urges in response to the rollercoaster scene $(M=1.52, S D=0.57)$ were significantly lower $(p=0.034)$, and urges in response to the losing scenario $(M=1.71, S D=0.57)$ fell in between and did not differ from either the win $(p=0.193)$ or rollercoaster $(p=0.917)$ scenario $[F(2,59)=3.34, p=0.042$, $\left.\eta^{2}=0.10\right]$. Finally, the social gamblers reported a greater urge to gamble to the winning scenario $(M=3.57, S D=0.69)$; urges in response to the losing scenario $(M=2.19$, $S D=0.57)$ and the rollercoaster scene $(M=2.24, S D=0.57)$ were both lower ( $p=0.007$ and $p=0.003$, respectively) and did not differ from each other $(p=0.998)$ $\left[F(2,59)=6.48, p=0.0 .003, \eta^{2}=0.18\right]$.

In summary, the three groups showed similar cue-elicited heart rate increases, regardless of the cue. All three groups rated the win and the rollercoaster scenarios as more exciting than the lose scenario. Only the active pathological gamblers reported overall significantly greater cue-elicited urges to gamble than the abstinent pathological gamblers and (with marginal significance, $p=0.06$ ) the social gamblers. Most importantly, compared to the losing scenario, they reported significantly greater urges to gamble in response to both the exciting winning and the exciting rollercoaster scenario, a pattern that was not observed in the abstinent or the social gamblers.

\section{Discussion}

In this study, active and abstinent pathological gamblers as well as social gamblers did not show significant differences in cue-elicited heart rate arousal. All three groups, regardless 
of gambling status, showed comparable modest increases in heart rates to the cues, with no significant differences in their reactions to the winning and losing gambling scenarios and the rollercoaster scene. The absence of cue-specific reactivity in heart rate is consistent with previous laboratory research that has failed to find heart rate differences between problem and regular gamblers in response to various gambling cues (Sharpe et al. 1995; Wulfert et al. in press). One plausible hypothesis is that gambling cues in experimental analogue settings elicit only weak physiological reactions if the cue presentation does not signal the possibility of a consequence. This stands in contrast to experimental research that involves actual wagering. For example, much stronger heart rate increases have been shown in the laboratory when participants actually wagered a small amount, and heart rates were significantly higher after winning than losing money (Wulfert et al. 2005, 2008). Even more dramatic increases in heart rate have been shown with gamblers in a real-world gambling establishment (e.g., casino, racetrack) compared to a laboratory setting (Anderson and Brown 1984).

Cue-specific reactivity was observed for excitement. Participants in all three groups found the winning gambling scenario and the thrilling rollercoaster ride more exciting than the rather depressing gambling scenario that involved losing money. However, it should be noted that excitement was not specific to the cue of an exciting gambling scene but was also elicited by a generic exciting scene (here a rollercoaster ride). Moreover, active pathological gamblers did not report more excitement to the image of winning a lot of money during gambling than the abstinent pathological gamblers or the social gamblers. On the one hand, this might seem somewhat surprising because anecdotal evidence suggests that gambling and winning can induce euphoric arousal, particularly in problem gamblers. On the other hand, it is obvious that cues presented in an experimental analogue situation do not elicit the same reactivity than cues in a realistic gambling environment, given that there is a fundamental difference between imagining having won a sum of money and indeed having won it. It would require a replication in a real-world setting such as a racetrack or casino where gamblers are betting real money for real payouts and losses (i.e., consequences) to find a more definitive answer as to whether pathological gamblers differ from social and abstinent gamblers in the degree of physiological and psychological arousal elicited by gambling cues. For ethical reasons such a study would be difficult to conduct.

A second interesting finding of this study was that the three groups reported different degrees of urge to gamble in response to the cues. First, it is important to note that the active pathological gamblers reported an overall significantly higher urge to gamble than the abstinent pathological gamblers and the social gamblers. The same finding has recently been reported in another cue-reactivity study comparing pathological and regular gamblers (Wulfert et al. in press) and supports the assumption that active pathological gamblers may be more sensitized and experience greater motivation to gamble than other individuals.

For all three groups the winning scenario elicited the strongest urge to gamble, but it was interesting that for the active pathological gamblers the exciting rollercoaster scenario also elicited an urge to gamble that was significantly stronger than the urge in response to the losing scenario. This suggests that pathological gamblers, in contrast to regular gamblers, may experience an urge to gamble not just when confronted with gambling-related stimuli but also with other situations that induce a sense of excitement or exhilaration. We speculate that active pathological gamblers through classical conditioning have developed a strong association between gambling and excitement due to the frequency and duration of gambling episodes (Wikler 1973); hence, the feeling of excitement elicited by other sources immediately reminds them of gambling and excitement itself has become a cue for 
the urge to gamble. In contrast, for the abstinent pathological gamblers in the present study whose last gambling episode occurred an average of 2.5 years ago, this association apparently had been extinguished, i.e., replaced by new learning, maybe in the form of a competing coping or a bridging response that interfered with the experience of excitement to these cues (e.g., Bouton et al. 2006).

The process of extinction may also explain why the abstinent pathological gamblers reported overall the lowest urge to gamble. While it is well known that extinction does not destroy the original learning and can be remarkably context specific, exposure to many relevant contextual cues over the course of extinction may lead to generalization (Bouton et al. 2006). With time, abstinent pathological gamblers have likely successfully resisted urges elicited by a multitude of gambling-related cues, given their ubiquity in our society. This interpretation is consistent with findings from the addiction literature that cravings for alcohol and other substances often diminish as time of abstinence increases (e.g., Anton et al. 1996; O'Brien et al. 1990).

In sum, this study did not find noticeable differences in cued physiological arousal and excitement among active pathological, abstinent pathological, and social gamblers. All three groups reacted with similar heart rate increases to the three cues and all rated the winning and the exhilarating rollercoaster scene more exciting than the losing scenario. However, the study did find that active pathological gamblers differ from abstinent pathological gamblers and regular social gamblers by responding with significantly stronger urges to gamble. These urges are stronger not only when they encounter exciting gambling-related but also exciting non-gambling related cues. Finally, the study also suggests that these reactions are reversible if pathological gamblers maintain a significant period of abstinence.

\section{Limitations}

The findings should be considered in light of several limitations. The study was conducted in the laboratory and participants were asked to imagine themselves in specific gambling or non-gambling situations while watching corresponding scenarios on a computer screen. Although the scenarios were comprised of vivid visual and auditory materials, the participants' physiological and psychological reactions might have been significantly stronger in a naturalistic setting and additional significant differences between groups of gamblers might have been found. However, exposing treatment-seeking or abstinent pathological gamblers to a real-world gambling environment would not have been feasible due to ethical concerns. Perhaps technological advancements and more realistic virtual environments may allow for the creation of more potent stimulus materials in the future.

A second limitation was that we only asked participants to give a numerical rating (0-10) for their state of relaxation after the first baseline and not after the two returns to baseline. While the experimenter monitored the HRs on the receiver, in future research it would be desirable to repeat the relaxation question after each return to baseline since it is possible that some participants might experience a subjective feeling of anxiety or agitation after being exposed to gambling scenes that would interfere with a subjective state of relaxation, even when the HR has returned to baseline.

A final limitation may be that participants included gamblers with a wide range of gambling preferences, from horse race betting to scratch-off lottery to online gambling. It may be erroneous to treat gambling as a unitary construct. Each type of gambling may attract individuals with their own distinct pattern of reacting to gambling-specific cues, and 
grouping all gamblers together regardless of their gambling preferences may have obscured existing differences.

\section{Future Directions}

Despite limitations, this study has made a contribution to the cue reactivity literature. It is to date the largest of only four controlled cue reactivity studies focusing on pathological gambling, and it is the only study to compare active and abstinent pathological gamblers. Future research should seek to replicate the findings, using more homogeneous samples of gamblers and, where possible, conducting research in real-world settings. In addition, as pathological gambling appears to fit well within the cue reactivity paradigm, future research should also evaluate cue exposure and response prevention as one possible modality in a comprehensive treatment for this disorder.

Open Access This article is distributed under the terms of the Creative Commons Attribution Noncommercial License which permits any noncommercial use, distribution, and reproduction in any medium, provided the original author(s) and source are credited.

\section{Appendix}

\section{Slot Machine Winning Scenario}

Imagine - as vividly as you can - a time when you won a large amount of money playing the slot machines, more money than you had ever won before.

Go back in time and visualize in your mind's eye what happened that day. Remember the casino. Remember the familiar color of the carpets, the dim interior, the flashing lights and sounds of the slot machines.

Imagine yourself deciding which slot machine to play on. Remember the surge of energy that is sweeping through your body as you are scanning the machines, contemplating all of the money just waiting to be won. The thought makes your heart quicken. You settle on the machine you have a good hunch about. You start playing, putting in the money...Y You are filled with anticipation as you are watching the wheels spin. Feel your heart beating fast with excitement, the feeling it makes in your chest! Your breath is coming quick and your heart is beating faster and faster as you just barely miss hitting the jackpot! You put all your concentration on the wheels of the machine as they spin. And then... you hear the sounds of the bells ringing! You have hit the jackpot! Your heart is pounding now, and you feel a rush of warmth spread throughout your body. People are turning to look at you, seeing that you've won! You have done it! You've won so much money! More money than you have ever won before!

Now remember the excitement as you are cashing in. Look at all the money that you have won! Touch it! Count it! Your heart is still racing and your mind is racing too as you see all this money that is now yours. Experience what it feels like to win all that money.

Now take that scene away.

\section{References}

American Psychiatric Association. (2000). Diagnostic and statistical manual of mental disorders (4th ed. Text Revision). Washington, D.C.: American Psychiatric Association.

Anderson, G., \& Brown, R. I. (1984). Real and laboratory gambling, sensation-seeking and arousal. British Journal of Psychology, 75(Pt 3), 401-410. 
Anton, R. F., Moak, D. H., \& Latham, P. K. (1996). The obsessive compulsive drinking scale: A new method of assessing outcome in alcoholism treatment studies. Archives of General Psychiatry, 53(3), 225-231.

Blanchard, E. B., Wulfert, E., Freidenberg, B. M., \& Malta, L. S. (2000). Psychophysiological assessment of compulsive gamblers' arousal to gambling cues: A pilot study. Applied Psychophysiology and Biofeedback, 25(3), 155-165.

Blaszczynski, A., McConaghy, N., \& Frankova, A. (1991). A comparison of relapsed and non-relapsed abstinent pathological gamblers following behavioural treatment. British Journal of Addiction, 86(11), 1485-1489.

Bouton, M. E. (2004). Context and behavioral processes in extinction. Learning and Memory, 11, 485-494.

Bouton, M. E., Woods, A. M., Moody, E. W., Sunsay, C., \& García-Gutiérrez, A. (2006). Counteracting the context-dependence of extinction: Relapse and tests of some relapse prevention methods. In M. G. Craske, D. Hermans, \& D. Vansteenwegen (Eds.), Fear and learning: From basic processes to clinical implications (pp. 175-196). Washington, DC: American Psychological Association.

Brandon, T. H., Piasecki, T. M., Quinn, E. P., \& Baker, T. B. (1995). Cue exposure treatment in nicotine dependence. In D. C. Drummond, S. Tiffany, S. Glautier, \& B. Remington (Eds.), Addictive behavior: Cue exposure theory and practice (pp. 211-227). Chichester: Wiley.

Carter, B. L., \& Tiffany, S. T. (1999). Meta-analysis of cue-reactivity in addiction research. Addiction, 94(3), 327-340.

Childress, A. R., McLellan, A. T., \& O’Brien, C. P. (1986). Role of conditioning factors in the development of drug dependence. Psychiatric Clinics of North America, 9, 413-425.

Coventry, K. R., \& Norman, A. C. (1997). Arousal, sensation seeking and frequency of gambling in offcourse horse racing bettors. British Journal of Psychology, 88(Pt 4), 671-681.

Daughters, S. B., Lejuez, C. W., Strong, D. R., Brown, R. A., Breen, R. B., \& Lesieur, H. R. (2005). The relationship among negative affect, distress tolerance, and length of gambling abstinence attempt. Journal of Gambling Studies, 21(4), 363-378.

Dawe, S., \& Powell, J. (1995). Cue exposure treatment in opiate and cocaine dependence. In D. C. Drummond, S. Tiffany, S. Glautier, \& B. Remington (Eds.), Addictive behaviour: Cue exposure theory and practice (pp. 197-209). Chichester: Wiley.

Dickerson, M., \& Adcock, S. (1987). Mood, arousal, and cognitions in persistent gambling: Preliminary investigation of a theoretical model. Journal of Gambling Behavior, 3(1), 3-15.

Drummond, S., Tiffany, S. T., Glautier, S., \& Remington, B. (1995). Cue exposure in understanding and treating addictive behaviors. In D. C. Drummond, S. Tiffany, S. Glautier, \& B. Remington (Eds.), Addictive behaviors: Cue exposure theory and practice (pp. 1-17). Chichester: Wiley.

Ethofer, T., Pourtois, G., \& Wildgruber, D. (2006). Investigating audiovisual integration of emotional signals in the human brain. Progress in Brain Research, 156, 345-361.

Gingras, G., Rowland, B. A., \& Stein, B. E. (2009). The differing impact of multisensory and unisensory integration on behavior. The Journal of Neuroscience, 29(15), 4897-4902.

Hodgins, D. C., Peden, N., \& Cassidy, E. (2005). The association between comorbidity and outcome in pathological gambling: A prospective follow-up of recent quitters. Journal of Gambling Studies, 21(3), $255-271$.

Kuntze, M. F., Stoermer, R., Mager, R., Roessler, A., Mueller-Spahn, F., \& Bullinger, A. H. (2001). Immersive virtual environments in cue exposure. Cyberpsychology and Behavior, 4(4), 497-501.

Ladouceur, R., Sevigny, S., Blaszczynski, A., O’Connor, K., \& Lavoie, M. E. (2003). Video lottery: Winning expectancies and arousal. Addiction, 98(6), 733-738.

Leary, K., \& Dickerson, M. (1985). Levels of arousal in high- and low-frequency gamblers. Behaviour Research and Therapy, 23(6), 635-640.

Lee, J. H., Ku, J., Kim, K., Kim, B., Kim, I. Y., Yang, B. H., et al. (2003). Experimental application of virtual reality for nicotine craving through cue exposure. Cyberpsychology and Behavior, 6(3), 275280.

McLellan, A. T., Kushner, H., Metzger, D., Peters, R., Smith, L., Grissom, G., et al. (1992). The fifth edition of the addiction severity index: Historical critique and normative data. Journal of Substance Abuse Treatment, 9, 199-213.

Miller, J. O. (1986). Time course of coactivation in bimodal divided attention. Perception and Psychophysics, 40, 331-343.

Moodie, C., \& Finnigan, F. (2005). A comparison of the autonomic arousal of frequent, infrequent and nongamblers while playing fruit machines. Addiction, 100(1), 51-59.

National Opinion Research Center (1999). Report to the national gambling impact study commission: Gambling impact and behavior study. 
O'Brien, C. P., Childress, A. R., McLellan, T., \& Ehrman, R. (1990). Integrating systemic cue exposure with standard treatment in recovering drug dependent patients. Addictive Behaviors, 15(4), 355-365.

Petry, N. M. (2003). Patterns and correlates of gamblers anonymous attendance in pathological gamblers seeking professional treatment. Addictive Behaviors, 28(6), 1049-1062.

Robbins, S. J., Ehrman, R. N., Childress, A. R., Cornish, J. W., \& O’Brien, C. P. (2000). Mood state and recent cocaine use are not associated with levels of cocaine cue reactivity. Drug and Alcohol Dependence, 59(1), 33-42.

Rohsenow, D. J., Monti, P. M., \& Abrams, D. B. (1995). Cue exposure treatment in alcohol dependence. In D. C. Drummond, S. Tiffany, S. Glautier, \& B. Remington (Eds.), Addictive behavior: Cue exposure theory and practice (pp. 169-196). Chichester: Wiley.

Rohsenow, D. J., Niaura, R. S., Childress, A. R., Abrams, D. B., \& Monti, P. M. (1990). Cue reactivity in addictive behaviors: Theoretical and treatment implications. The International Journal of the Addictions, 25(7A-8A), 957-993.

Schroger, E., \& Widmann, A. (1998). Speeded responses to audiovisual signal changes result from bimodal integration. Psychophysiology, 35(6), 755-759.

Sharpe, L. (2004). Patterns of autonomic arousal in imaginal situations of winning and losing in problem gambling. Journal of Gambling Studies, 20(1), 95-104.

Sharpe, L., Tarrier, N., Schotte, D., \& Spence, S. H. (1995). The role of autonomic arousal in problem gambling. Addiction, 90(11), 1529-1540.

Siegel, S. (1979). The role of conditioning in drug tolerance and addiction. In J. D. Keehn (Ed.), Psychopathy in animals: Research and treatment implications (pp. 143-168). New York: Academic Press.

Stewart, J., deWit, H., \& Eikelboom, R. (1984). The role of unconditioned and conditioned drug effects in the self-administration of opiates and stimulants. Psychological Review, 91, 51-268.

Wikler, A. (1965). Conditioning factors in opiate addiction and relapse. In D. I. Wilner \& G. G. Kassenbaum (Eds.), Narcotics (pp. 85-100). New York: McGraw-Hill.

Wikler, A. (1973). Dynamics of drug dependence. Archives of General Psychiatry, 28, 611-616.

Wulfert, E., Franco, C., Roland, B., \& Hartley, J. (2008). The role of money in the excitement of gambling. Psychology of Addictive Behaviors, 22(3), 380-390.

Wulfert, E., Franco, C., Sodano, R., Harris, K., Blanco, C., \& Blanchard, E. (in press). Retaining pathological gamblers in treatment: Cognitive-motivational behavior therapy. Psychology of Addictive Behaviors.

Wulfert, E., Maxson, J., \& Jardin, B. (in press). Cue-specific reactivity in experienced gamblers. Psychology of Addictive Behaviors.

Wulfert, E., Roland, B. D., Hartley, J., Wang, N., \& Franco, C. (2005). Heart rate arousal and excitement in gambling: Winners versus losers. Psychology of Addictive Behaviors, 19(3), 311-316. 